\title{
Mechanochemical Synthesis of Visible Light Sensitive Titanium Dioxide Photocatalyst
}

\author{
Jan Šubrt, ${ }^{1}$ Jose M. Criado, ${ }^{2}$ Lórant Szatmáry, ${ }^{1}$ Maria J. Diánez-Millán, ${ }^{2}$ Nataliya Murafa, ${ }^{1}$ \\ Luis A. Pérez-Maqueda, ${ }^{2}$ and Vlasta Brezová ${ }^{3}$
}

${ }^{1}$ Centre of Instrumental Techniques, Institute of Inorganic Chemistry of the AS CR, v.v.i., 25068 Řež, Czech Republic

${ }^{2}$ Department of Mechanochemistry and Reactivity of Materials, Instituto de Ciencias de Materiales de Sevilla C.S.I.C., Americo Vespucio s/n, Isla de la Cartuja, 41092 Sevilla, Spain

${ }^{3}$ Institute of Physical Chemistry and Chemical Physics, Faculty of Chemical and Food Technology,

Slovak University of Technology in Bratislava, Radlinského 9, 81237 Bratislava, Slovakia

Correspondence should be addressed to Jan Šubrt, subrt@iic.cas.cz

Received 2 September 2010; Accepted 3 March 2011

Academic Editor: Shahed Khan

Copyright () 2011 Jan Šubrt et al. This is an open access article distributed under the Creative Commons Attribution License, which permits unrestricted use, distribution, and reproduction in any medium, provided the original work is properly cited.

\begin{abstract}
Phase transition of anatase nanoparticles into the phases $\mathrm{TiO}_{2}$-II and rutile under grinding was studied. The addition of ammonium carbamate to the reaction mixture inhibits the phase conversion and the cold welding of particles. The UV-visible absorption spectrum showed narrowing the band gap width after grinding with an ammonium carbamate additive resulting in shift of the light absorption of the ground sample towards the visible region. By EPR, intensive formation of $\mathrm{OH}^{\bullet}$ radical at irradiation of the sample with both $\mathrm{UV}(\lambda>300 \mathrm{~nm})$ and visible $(\lambda>435 \mathrm{~nm})$ light was observed. High photocatalytic activity of the ground sample in visible light region was demonstrated also by measurement of kinetics of the photocatalytic decomposition of 4-chlorophenol.
\end{abstract}

\section{Introduction}

Titanium dioxide attracted a great attention since Fujishima and Honda discovered in 1972 the photocatalytic splitting of water on $\mathrm{TiO}_{2}$ electrode [1]. In the last two decades, the application of nanosized $\mathrm{TiO}_{2}$ focused on environmental remediation, especially water detoxification and air purification (both indoor and outdoor), commanded attention to these phenomena [2-8]. $\mathrm{TiO}_{2}$ is an efficient photocatalyst, but UV light is necessary for its activation owing to a rather wide band gap energy $(\sim 3.2 \mathrm{eV})$. Solar energy contains only about $4 \% \mathrm{UV}$, light and much of the rest is visible light. In order to utilize the visible (solar) light efficiently for the photocatalytic reactions, titanium dioxide has to be modified in order to lower the energy necessary for excitation of the electron into the conduction band. There have been described several approaches how to modify $\mathrm{TiO}_{2}$ with this respect. Several authors substituted $\mathrm{Ti}^{4+}$ in $\mathrm{TiO}_{2}$ by metal ion implantation (e.g., $\mathrm{Cr}^{3+}$ or $\mathrm{V}^{3+}$, lanthanides, etc.) [9-11]. It was demonstrated that the absorption band of $\mathrm{Cr}^{3+}$-doped $\mathrm{TiO}_{2}$ shifted and that $\mathrm{NO}_{x}$ decomposed giving rise to $\mathrm{N}_{2}, \mathrm{O}_{2}$, and $\mathrm{N}_{2} \mathrm{O}$ as the result of the photocatalytic reaction under visible light irradiation with wavelength larger than $450 \mathrm{~nm}$.

$\mathrm{N}$-doped titania photocatalyst sensitive to visible light irradiation was described in 2001 by Asahi et al. [12, 13]. The authors proved that nitrogen doping leads to narrowing of band gap by mixing the $\mathrm{N} 2 \mathrm{p}$ and $\mathrm{O} 2 \mathrm{p}$ states and consequently to induction of the visible-light responsive photocatalytic activity. It was also forecasted that other kinds of anions such as $\mathrm{C}, \mathrm{S}$, and $\mathrm{F}$ would result in a similar effect to nitrogen. Afterwards, various types of visible light sensitive $\mathrm{TiO}_{2}$ photocatalysts doped with anions such as sulphur and carbon have been widely studied [14-22]. The structure of $\mathrm{N}$-doped $\mathrm{TiO}_{2}$ as well as the effect of $\mathrm{N}$ doping on $\mathrm{TiO}_{2}$ photoactivity has been discussed in many recent papers, for example, [23-25] and reviews [26, 27]. At present, there exist hundreds of papers and patents describing successful preparation of visible light sensitive 


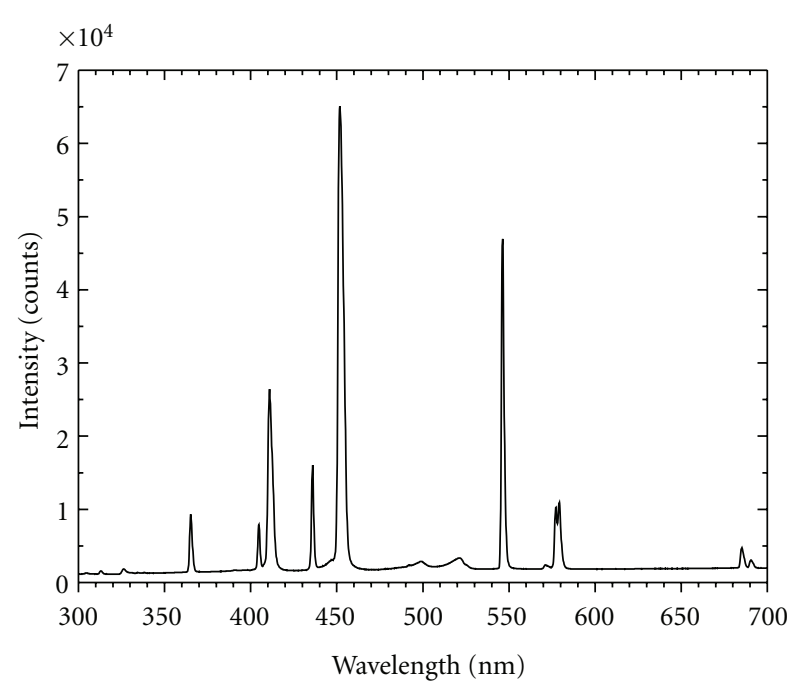

_ Nana 400 W blue lamp

(a)

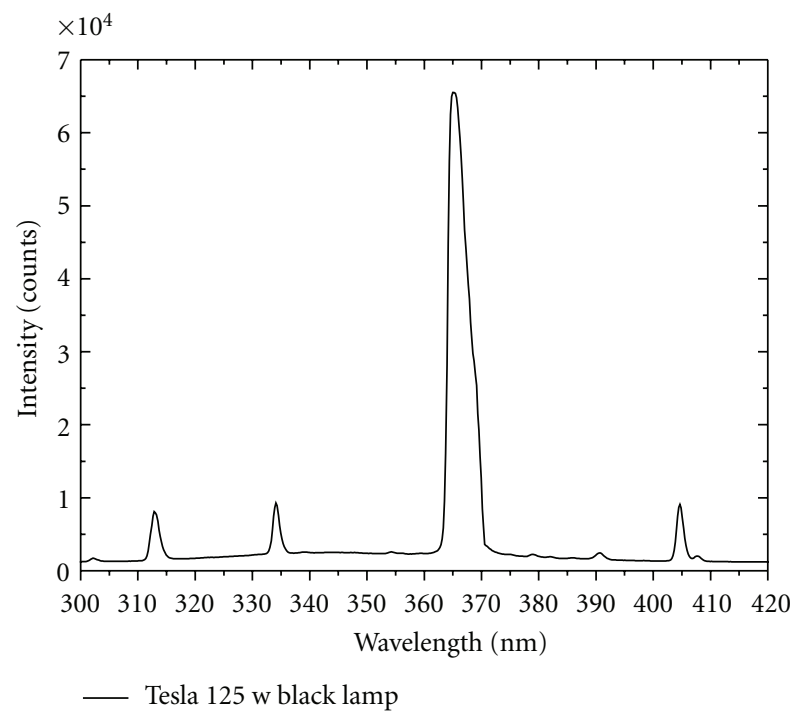

(b)

FIGURE 1: The light spectrum of sources used for determination of photocatalytic activity.

photocatalysts. However, most preparation methods used are high temperature processes or using expensive precursors or preparation instruments. According to our experience, the enhanced photoactivity in the visible light region is often compensated by sinking the activity at the UV light irradiation; therefore, the overall photoactivity of such material at sun light is often significantly lower in comparison to highly effective photocatalysts like, for example, DEGUSSA AEROXIDE $\mathrm{TiO}_{2}$ P 25. Hence, synthesis of highly active visible light sensitive photocatalyst should be still considered as an actual problem to be solved.

The measurement of rate of decomposition of various dyes is often used for determination of visible light activity of the photocatalysts. As it was demonstrated recently, such approach can lead to serious errors owing to possible

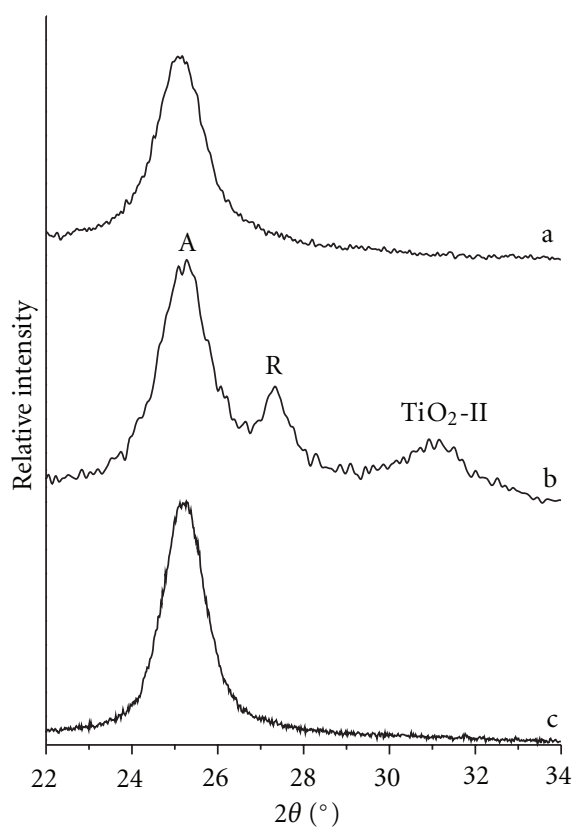

FIgURE 2: XRD diagrams of the starting $\mathrm{TiO}_{2}$ sample-TIT 144 (a) and the samples ground for 1.6 hours without additives (b) and with ammonium carbamate-TIT 144 ground (c), respectively.

dye-sensitization of the photocatalyst to visible light or injection of the photoexcited electrons from dyes directly to the photocatalyst particles $[28,29]$. In this study the photocatalyzed decomposition of 4-chlorophenol is used as model reaction owing to stability of this compound under the reaction conditions to UV light as well as availability of many data in the literature using 4-chlorophenol as the model compound to determine the titania photocatalyst activity in the UV region.

It is well known that the activation of chemical reactions by mechanical energy can lead to many interesting applications, ranging from waste processing to the production of advanced materials with novel microstructures and enhanced mechanical properties [30]. Among other phenomena, mechanical energy can induce phase transformation and growth of nanocrystals in titania powder as well as change their surface properties [31-34]. It has been observed that mechanical treatment also affect significantly the photoactivity of titanium dioxide $[35,36]$.

Recently we studied mechanically activated anatase $\rightarrow$ rutile phase transformations using phase pure anatase [37] supplied by Aldrich. We observed that the anatase $\rightarrow$ rutile phase transformation was significantly hindered by presence of ammonium carbamate, whereas for the pure sample the transformation was complete within one hour of grinding, at presence of ammonium carbamate after 2.5 hours only $40 \%$ of anatase has been transformed into rutile. Ammonium carbamate addition also caused decrease of crystallite size in the ground products at otherwise similar grinding conditions. We also observed that the anatase $\rightarrow$ rutile phase transformation of nanocrystalline anatase at the same 
grinding conditions proceeds significantly more slowly and the products are yellow coloured.

\section{Experimental}

2.1. Chemicals. For the grinding experiments we used nanocrystalline anatase prepared by homogeneous preci-pitation of $\mathrm{TiOSO}_{4}$ aqueous solutions with urea at $100^{\circ} \mathrm{C}$. $\mathrm{TiOSO}_{4}$ $(30 \mathrm{~g})$ was dissolved in $100 \mathrm{~mL}$ hot water acidified with $98 \%$ $\mathrm{H}_{2} \mathrm{SO}_{4}$. The pellucid liquid was diluted into $4 \mathrm{~L}$ of distilled water and mixed with $200 \mathrm{~g}$ of urea. The mixture was heated to $100^{\circ} \mathrm{C}$ under stirring and kept at this temperature for $6 \mathrm{hrs}$ until $\mathrm{pH} 7$ was reached and ammonia escaped from the solution. The precipitates formed have been thoroughly washed with distilled water, filtered off, and dried at laboratory temperature. The precipitate consists of crystalline anatase nanoparticles with diameter $4-6 \mathrm{~nm}$, the nanoparticles are aggregated into firm spherical clusters $\sim 2 \mu \mathrm{m}$ diameter, specific surface area of the sample is $200-300 \mathrm{~m}^{2} / \mathrm{g}$. The material contains $\sim 0.1-0.5 \%$ by wt. of strongly bound $\mathrm{SO}_{4}^{2-}$ and does not contain any nitrogen containing compound, for example, urea or $\mathrm{NH}_{4}^{+}$salts (sample TIT 144). The detailed description of the preparation procedure and apparatus used as well as properties of the precipitate is given in our previous reports [38-40].

The standard materials DEGUSSA AEROXIDE $\mathrm{TiO}_{2} \mathrm{P}$ 25 photocatalyst and nanocrystalline anatase $\mathrm{BDH}[41]$ were used for comparing the photocatalytic activity of samples.

4-chlorophenol for photocatalytic activity tests (99\%) was purchased from Fluka (Germany) and used without further purification.

The spin trapping agent, 5,5-dimethyl-1-pyrroline $\mathrm{N}$ oxide (DMPO, Aldrich), was freshly distilled before application and stored under argon. The concentration of photogenerated adducts was determined using as calibration standards aqueous solutions of 4hydroxy-2,2,6,6-tetramethylpiperidine $\mathrm{N}$-oxyl free radical (TEMPOL; Aldrich) measured under strictly identical EPR instrument settings.

2.2. The Grinding Experiments. A high grinding energy planetary ball mill Pulverisette 7 (Fritsch, Germany), has been used. Steel grinding bowls with $45 \mathrm{~mL}$ volume and $40 \mathrm{~mm}$ in inner diameter charged with 7 steel balls of $15 \mathrm{~mm}$ in diameter were used. Ball weight/sample weight ratios close to 20 and a rotation speed of $700 \mathrm{rpm}$ have been used. The sample "TIT 144 ground" was prepared by grinding the sample TIT 144 for $1.7 \mathrm{hrs}$ with addition of $20 \%$ by wt. of ammonium carbamate. In order to clean the surface from possible rests of the grinding additive, the sample was subjected to subsequent annealing at $400^{\circ} \mathrm{C}$ for $1 \mathrm{hr}$ in an air atmosphere.

2.3. Physical Characterization of the Materials. The X-ray diffractions diagrams were recorded with a PHILPS X'pert Pro equipped with a X'celerator. $\mathrm{Cu} \mathrm{K}_{\alpha}$ radiation and a nickel filter were used. A voltage of $40 \mathrm{kV}$ and an intensity of $40 \mathrm{~mA}$ were employed. The percentages of anatase, rutile, and the high pressure Titania phase $\left(\mathrm{TiO}_{2} \mathrm{II}\right)$ with structure $\alpha-\mathrm{PbO}_{2}$ were determined by the direct method [42] from

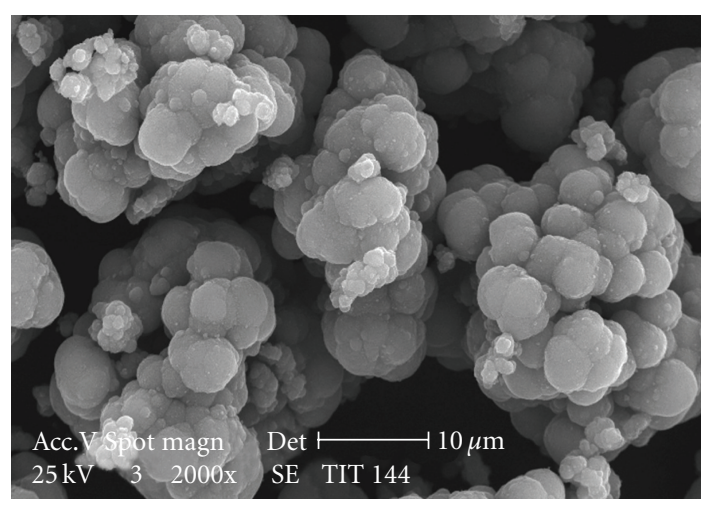

(a)

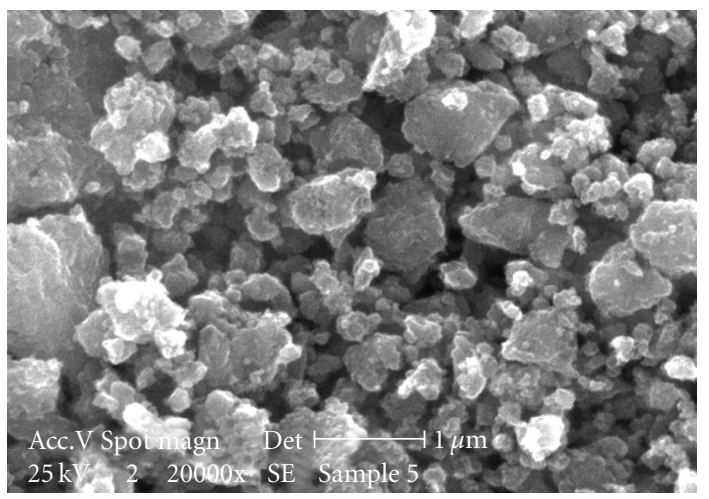

(b)

Figure 3: SEM micrographs of samples TIT 144 (initial)—(a) and TIT 144 ground-(b).

the intensity of the diffraction peaks (110) of rutile, (101) of anatase, and (111) of the $\mathrm{TiO}_{2}$-II phase. The crystal sizes were determined from the integral broadening of the diffraction peaks corresponding to the planes (101) of anatase, (110) of rutile, and (111) of the $\mathrm{TiO}_{2}$-II phase, respectively.

Transmission electron micrographs were obtained using a JEOL JEM 3010 microscope operating at accelerating voltage of $300 \mathrm{kV}$. The samples for electron microscopy were prepared by grinding and subsequent dispersing of the powder in propyl alcohol and applying a drop of very dilute suspension on carbon-coated grids. The suspensions were dried by slow evaporation at ambient temperature.

The SEM micrographs were obtained using Philips XL 30 CP equipped with EDX, SE, BSE, and Robinson detectors. The powder samples were studied in native form without coating by conductive metal layers.

The B.E.T. surface area was measured by means of a Micromeritics equipment, model ASAPS 2010, using nitrogen as adsorbate at the liquid nitrogen temperature.

The X-ray Photoelectron Spectra (XPS) were recorded with a Vacuum Generators, model Escalab 210, equipment by using a $\mathrm{Mg} \mathrm{K} \alpha$ with a pass energy resolution of $50 \mathrm{eV}$. The spectra of the powder sample were recorded at room temperature under a residual pressure lower than $10^{-10}$ mbar. 


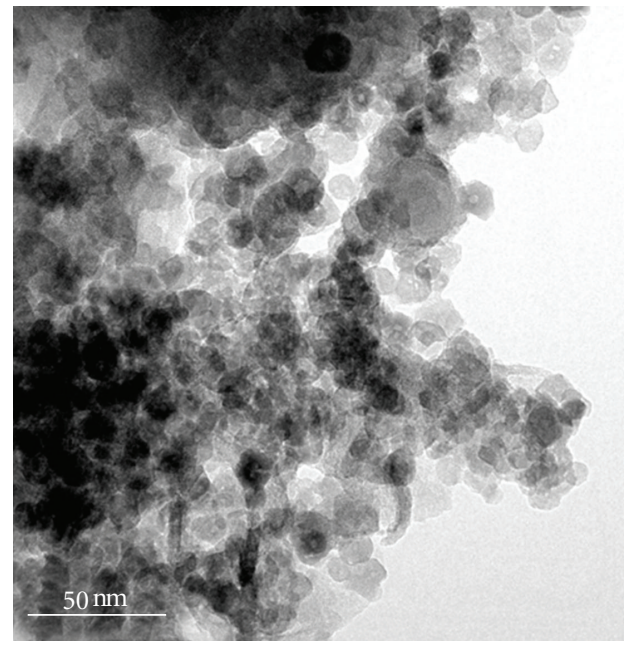

(a)

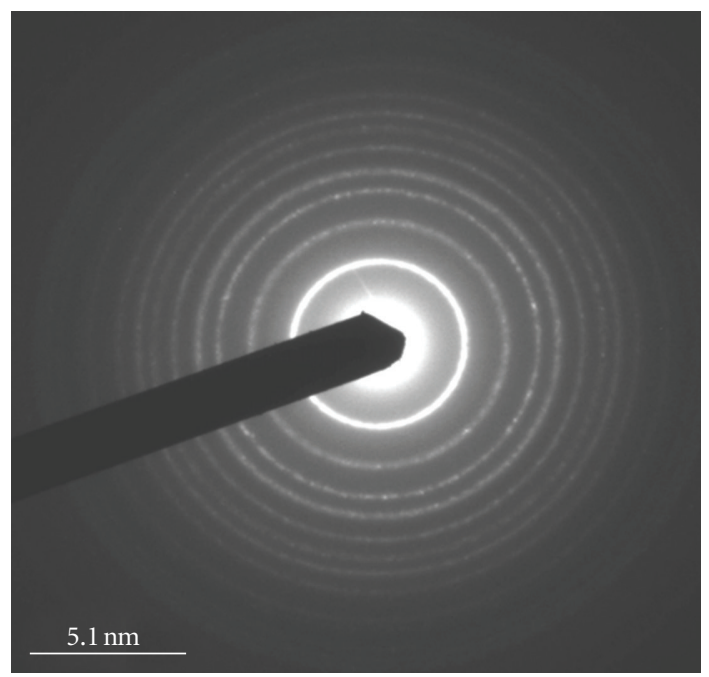

(c)

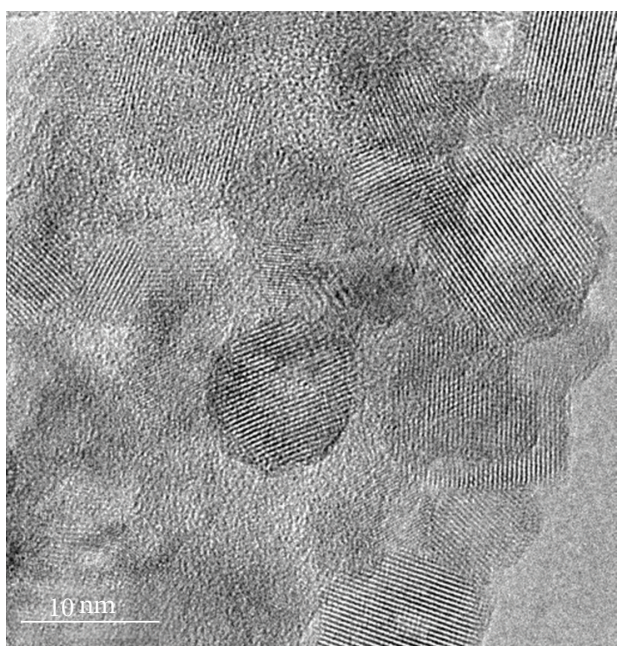

(b)

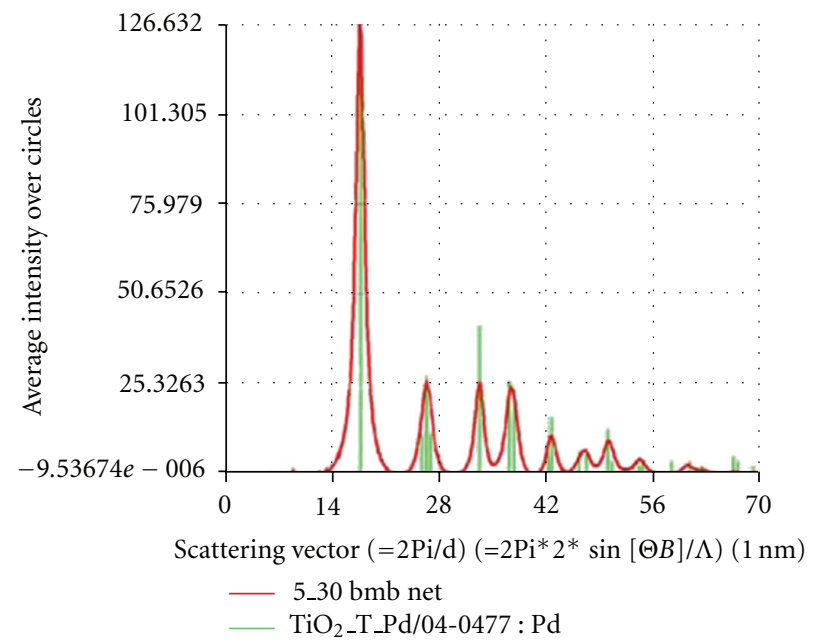

(d)

FIgURE 4: TEM micrographs $(\mathrm{a}, \mathrm{b})$ and electron diffraction pattern $(\mathrm{c}, \mathrm{d})$ of the sample TIT 144 ground.

2.4. Diffusion Reflectance Spectra and Band Gap Mesurements. UV-vis spectra were recorded in the diffuse reflectance mode with a Shimadzu AV2101 UV-vis spectrophotometer equipped with an integrating sphere, $\mathrm{BaSO}_{4}$ was used as reference. The spectra were taken in the diffuse reflectance mode $(R)$ and transformed to a magnitude proportional to the extinction coefficient $(K)$ through the Kubelka-Munk function, $F\left(R_{\alpha}\right)$. Band gap values were obtained from the plot of the modified Kubelka-Munk function, $\left(F\left(R_{\alpha}\right) E\right)^{1 / 2}$, versus the energy of the absorbed light $E$.

2.5. EPR Spectra Measurements. The formation of hydroxyl radicals upon irradiation of $\mathrm{TiO}_{2}$ aqueous suspensions was investigated by EPR spin trapping technique using DMPO. The instantly prepared $\mathrm{TiO}_{2}$ suspensions containing DMPO were carefully mixed by slight air stream and immediately transferred to a quartz flat cell (WG 808-Q, WilmadLabGlass, USA) optimized for the $\mathrm{TE}_{102}$ cavity. The samples were irradiated at $295 \mathrm{~K}$ directly in the EPR resonator, and
EPR spectra were recorded in situ using EMX X-band EPR spectrometer (Bruker, Germany). As an irradiation source an HPA 400/30S lamp (400 W, Philips) was used. The radiation flux was focused to obtain high intensity in the active part of $\mathrm{TE}_{102}$ cavity. A Pyrex glass filter (thickness of $1 \mathrm{~mm}$ ) was applied to eliminate radiation wavelengths below $300 \mathrm{~nm}$. A GG 435 filter (Schott Glaswerke, Germany) was used to cut off wavelengths shorter than $435 \mathrm{~nm}$. The stock suspensions were prepared by dispersing $10 \mathrm{mg} \mathrm{TiO}_{2}$ powder in 10 $\mathrm{ml}$ distilled water, and then carefully homogenized in an ultrasound bath (60 s, Ultrasonic Compact Cleaner TESON 1, Tesla, Slovak Republic) before use. The concentration of DMPO stock solutions was $0.2 \mathrm{~mol}^{-1}$. The experimental EPR spectra acquisition and their simulations were carried out using WIN EPR and SimFonia standard programs (Bruker).

2.6. Photocatalytic Activity Tests. Kinetics of decay of $0.1377 \mathrm{mmole} \cdot \mathrm{L}^{-1}$ solution of 4 -chlorophenol (4-CP) in 
TABLE 1: Phase composition $\left(\mathrm{X}_{\mathrm{A}}\right.$ fraction of anatase; $\mathrm{X}_{\mathrm{R}}$, rutile; $\mathrm{X}_{\mathrm{II}}, \mathrm{TiO}_{2}$-II phase), specific area $(\mathrm{S})$ and crystal size $\left(\mathrm{D}_{\mathrm{A}}\right.$, anatase; $\mathrm{D}_{\mathrm{R}}$, rutile and $\mathrm{D}_{\mathrm{II}}, \mathrm{TiO}_{2}$-II phase) of the different phases present at the as prepared sample and after grinding for 1.6 hours without additives (1.6 $\mathrm{h}$ ) and with ammonium carbamate additive (1.6 h AC), respectively.

\begin{tabular}{lccccccc}
\hline Sample & $\mathrm{X}_{\mathrm{A}}$ & $\mathrm{X}_{\mathrm{R}}$ & $\mathrm{X}_{\mathrm{II}}$ & $\mathrm{D}_{\mathrm{A}}(\mathrm{nm})$ & $\mathrm{D}_{\mathrm{R}}(\mathrm{nm})$ & $\mathrm{D}_{\mathrm{II}}(\mathrm{nm})$ & $\mathrm{S}\left(\mathrm{m}^{2} / \mathrm{g}\right)$ \\
\hline As prepared & 1.00 & - & - & 6.8 & - & - & 232 \\
$1.6 \mathrm{~h}$ & 0.35 & 0.35 & 0.30 & 7.1 & 5.7 & 5.1 & -1 \\
$1.6 \mathrm{~h} \mathrm{AC}$ & 1.00 & - & - & 8.0 & - & - \\
\hline
\end{tabular}

$60 \mathrm{~mL}$ of aerated aqueous suspension of mixtures with the tested photocatalysts $\left(1 \mathrm{~g} \cdot \mathrm{L}^{-1}\right)$ were monitored. The laboratory irradiation experiments were performed in a selfconstructed photo reactor at temperature $20^{\circ} \mathrm{C}$. It consists of two coaxial quartz tubes placed in the middle of a steel cylinder with an aluminum foil covering its inner wall. Inner quartz tube (diameter $24 \mathrm{~mm}$, length $300 \mathrm{~mm}$ ) was filled with the investigated suspension $(70 \mathrm{~mL})$ and magnetically stirred. Cooling water was circulating between the inner and the outer quartz tube to keep constant temperature of $20^{\circ} \mathrm{C}$. The detailed description of the photo reactor is given in [38]. Two light sources were used, NARWA $400 \mathrm{~W}$ Blue Lamp to determine the visible light activity and the TESLA $125 \mathrm{~W}$ Black lamp to determine the activity in the UV region. The light spectrum of these sources is shown on Figure 1. In order to remove weak UV lines in the Blue Lamp spectrum, filter formed by $0.1 \mathrm{~mole} \cdot \mathrm{L}^{-1}$ aqueous solution of $\mathrm{NaNO}_{2}$ was used. The light sources were placed close to the quartz tubes. By means of the ferric oxalate actinometry, an average light intensity entering the volume of $50-70 \mathrm{~mL}$ of the irradiated solution was determined as $I_{0}=5.3 \times$ $10^{-5}$ Einstein $\cdot \mathrm{dm}^{-3} \cdot \mathrm{s}^{-1}$. The $\mathrm{TiO}_{2}$ mixtures were sonicated for $20 \mathrm{~min}$ with a sonicator $(230 \mathrm{~W}, 30 \mathrm{kHz})$ before use. The $\mathrm{pH}$ of the resulting suspension was taken as the initial value for neutral conditions and under the experiment was kept at 7.00. $\mathrm{pH}$ was measured using an Alpha $500 \mathrm{pH}$ meter equipped with a glass $\mathrm{pH}$ electrode. Probes of irradiated suspensions $(1 \mathrm{~mL})$ were taken at appropriate irradiation times. The solid photocatalyst (necessarily together with the adsorbed portions of the dissolved molecular species) was removed before HPLC, employing filtration by a Millipore syringe adapter (diameter $13 \mathrm{~mm}$ ) with filter 408 (porosity $0.45 \mu \mathrm{m}$ ). The HPLC experiments were run on a Merck device with L-6200 Intelligent Pump, L-3000 Photo Diode Array Detector and D-2500 Chromato-Integrator. Mobile phase methanol/water $(2: 3, \mathrm{v} / \mathrm{v})$ and a Merck column LiChro-CART 125-4 filled with LiChrosphere 100 RP-18 $(5 \mathrm{~mm})$ were used, injection loop was $20 \mathrm{~mL}$, flow rate $1 \mathrm{~mL} \cdot \mathrm{min}^{-1}$ and detection wavelength $280 \mathrm{~nm}$ were applied.

\section{Results and Discussion}

3.1. XRD Results. Figure 2 shows the XRD diagram of the titania starting sample (TIT 144) together with the XRD diagrams of this sample after grinding 1.6 hours without additives and with $20 \%$ of ammonium carbamate as additive (TIT 144 ground), respectively. The crystal size and the phase composition determined from XRD data are included in Table 1 together with the specific surfaces determined from
B.E.T. measurements. These results show that the starting sample (TIT 144) is constituted by a single phase of anatase. The grinding of anatase leads to formation of $\mathrm{TiO}_{2}-\mathrm{II}$ and rutile, what would support that a mechanochemical transformation of anatase into rutile through the high pressure phase $\left(\mathrm{TiO}_{2}\right.$-II $)$ takes place as suggested in the literature $[43,44]$. On the other hand, the comparison of the phase composition and specific surface data of samples " $1.6 \mathrm{~h}$ " and "1.6 h AC" (sample TIT 144 ground) in Table 1 suggest that ammonium carbamate inhibits the phase conversion and the cold welding of particles during the grinding. Moreover, the crystal size measurements included in Table 1 suggest that ammonium carbamate promotes the recrystallization during the grinding of anatase, contrary to what occurs during the grinding without additives.

3.2. Electron Microscopy. The SEM micrographs on Figures $3(\mathrm{a})$ and 3(b) show size and shape of the $\mathrm{TiO}_{2}$ nanoparticle aggregates. The starting sample TIT 144 is formed by aggregates of spherical particles $\sim 10 \mu \mathrm{m}$ size whereas the ground sample TIT 144 ground (Figure 3(b)) consists of irregular-shaped particles ranging from $\mathrm{nm}$ to $\mu \mathrm{m}$ size.

The details of structure of nanoparticles of the sample TIT 144 ground can be seen on the TEM micrographs (Figures 4(a) and 4(b)) and ED patterns (Figures 4(c) and $4(d))$. We can see on this figure that the sample ground with ammonium carbamate consists of $\sim 10 \mathrm{~nm}$ randomly oriented anatase nanocrystals. Probably, amorphous part is present also in the aggregates; however, the particular nanoparticles are well crystalline even in the near surface regions. The electron diffraction pattern, in agreement with the XRD measurements, correspond well to anatase crystal structure.

The EDS analysis of the TIT 144 ground sample (Figure 5) shows that the material, except for $\mathrm{TiO}_{2}$, contains also low amount of $\mathrm{Fe}(0.3 \%)$ and $\mathrm{S}(0.6 \%)$. It is known that both these admixtures can shift the band gap energy to lower values, but concentrations used in experiments described in the literature are usually significantly higher [45]. The concentrations found in the TIT 144 ground sample are too low to explain the band gap shift to visible region and presence of high photoactivity under visible light radiation, as was demonstrated by EPR measurements and kinetics of the 4-CP decomposition.

3.3. Band Gap Determination. The results obtained for samples TIT 144 and TIT 144 ground are given on Figure 6. Significant shift of band gap width to lower values in comparison with the initial sample (from $3.2 \mathrm{eV}$ for the 
starting sample TIT 144 to $2.05 \mathrm{eV}$ for the sample TIT 144 ground) was observed. The results show that after grinding is carried out with an additive like ammonium carbamate that behaves as an ammonia supplier, the light absorption edge moves to the visible light region.

3.4. XPS Measurements. The XPS spectrum of the $\mathrm{N}_{1 \mathrm{~s}}$ band is shown in Figure 7. The analysis of this spectrum allows concluding that only nitrogen present on the surface as $\mathrm{NH}_{\mathrm{x}}$ radicals has been detected. The percentage of nitrogen determined from the XPS spectrum is $1.25 \%$.

3.5. EPR Measurements. The formation of highly reactive radical species under irradiation with UV or visible light on the surface of a photocatalyst is significant evidence of its photoactiovity. However, upon irradiation of aerated $\mathrm{TiO}_{2}$ aqueous suspensions, no paramagnetic signals of radicals are monitored using cw-EPR spectroscopy, due to the extremely short life-times of the reactive radical species generated. However, the photoproduced short-lived reactive radical intermediates may be evidenced by the spin trapping agents. The EPR spin trapping method involves the interaction of reactive short-lived free radicals with a diamagnetic EPRsilent compound (spin trap), via addition to a spin trap double bond, to produce a stable free radical product (spin adduct). The nature of the radical added can be identified after the analysis and simulation of the experimental EPR spectra [46]. The 5,5-dimethyl-1-pyrroline Noxide (DMPO) molecule possesses sufficient photostability under the given experimental conditions $(\lambda>300 \mathrm{~nm})$, since in a $\mathrm{TiO}_{2}$-free solution, negligible concentration of spin adducts are formed. The addition of photoactive titanium dioxide caused the generation of a four-line EPR signal upon irradiation, with spin Hamiltonian parameters characterized by the hyperfine splitting $a_{N}=1.495 \mathrm{mT}$, $a_{H}^{\beta}=1: 472 \mathrm{mT}$ and a $g$-value of 2.0057 , which are typical for hydroxyl radical adduct $(\bullet \mathrm{DMPO}-\mathrm{OH})$. The relative integral intensities of ${ }^{\circ} \mathrm{DMPO}-\mathrm{OH}$ adduct were evaluated by the double-integration procedure of experimental EPR spectra [47]. It is evident from Figure 8 showing the results of EPR measurement under filtered irradiation that intensive formation of $\mathrm{OH}^{\bullet}$ radical occur at irradiation of the sample by both $\mathrm{UV}(\lambda>300 \mathrm{~nm})$ as well as visible $(\lambda>435 \mathrm{~nm})$ light. This result documents well the photoactivity of the material even in the visible light region.

3.6. Decomposition of 4-Chlorophenol. The kinetic analysis of photocatalyzed decomposition of 4-chlorophenol has been carried out in terms of pseudofirst-order kinetics at the photostationary state. The 1st order reaction constant for photodegradation of 4-chlorophenol in water suspension was calculated for reaction in both visible and UV light.

From Figure 9 we can conclude that in the UV region the sample TIT 144 ground shows lowest activity with respect to both industrial photocatalysts tested, $\mathrm{BDH}$, and P25. However, the measured photoactivity is still remarkably higher in comparison to other visible light active photocatalysts we have tested earlier $[14,16]$. The photocatalytic activity measured under visible light shows reverse sequence

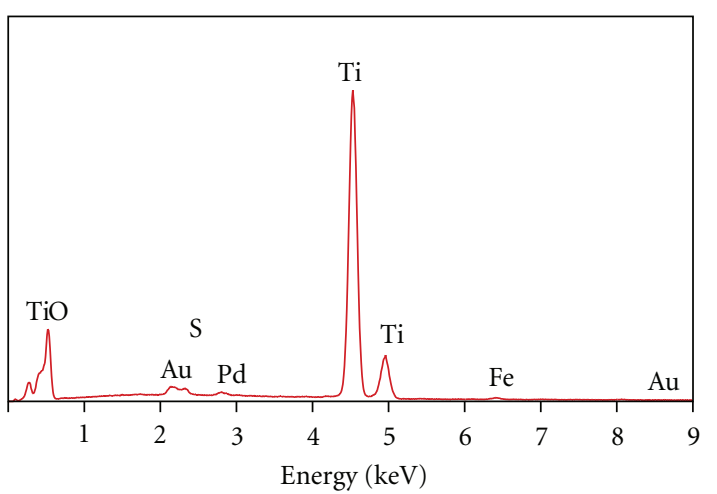

EDAX ZAF quantification (standardless) Element normalised SEC table : default

\begin{tabular}{crrclll} 
Element & Wt $\%$ & At $\%$ & K-ratio & Z & A & F \\
\hline O K & 37.79 & 65.59 & 0.0471 & 1.0984 & 0.1135 & 1 \\
S K & 0.59 & 0.51 & 0.005 & 1.0455 & 0.8009 & 1.0131 \\
PdL & 0.75 & 0.2 & 0.0067 & 0.8347 & 1.0417 & 1.0339 \\
TiK & 56.77 & 32.91 & 0.5274 & 0.9366 & 0.991 & 1.0009 \\
FeK & 0.58 & 0.29 & 0.0051 & 0.9346 & 0.9293 & 1.0013 \\
AuL & 3.51 & 0.49 & 0.0247 & 0.6925 & 1.0183 & 1
\end{tabular}

Figure 5: EDS analysis of the sample TIT 144 ground with ammonium carbamate addition.

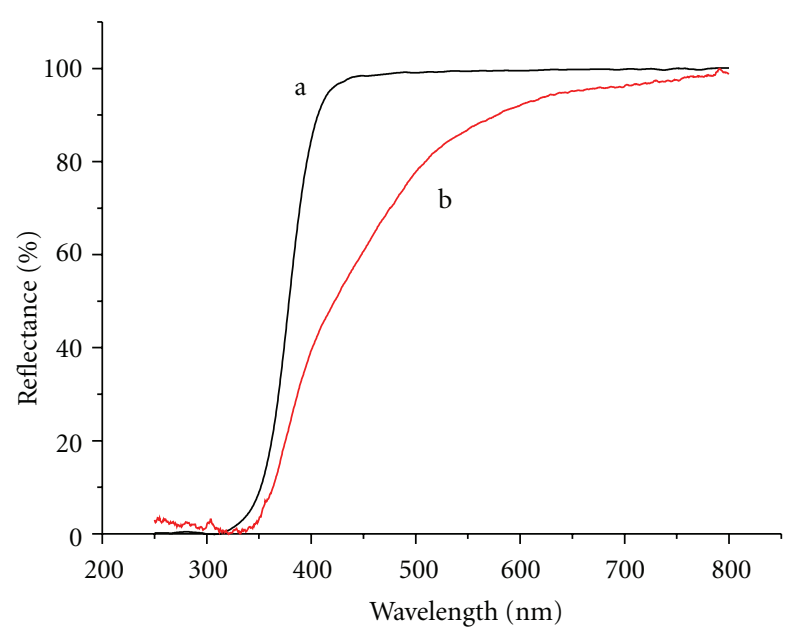

FIGURE 6: UV-vis spectra of the initial sample TIT 144 (a) and the sample TIT 144 ground ammonium carbamate addition (b).

of photocatalysts, the most active is the ground sample, whereas the P25 photocatalyst shows only very low activity in the visible light region and the $\mathrm{BDH}$ photocatalyst (pure nanocrystalline anatase) shows no measurable photoactivity in the visible light region with respect to decomposition of 4-chlorophenol.

As it can be concluded from EDS and XPS measurements, the sample TIT 144 ground contains as main impurities traces of $\mathrm{N}$ and Fe compounds, which were not detected in the initial sample. It is well known that both these elements could be responsible for increase of the photocatalytic activity under the visible light radiation $[12,13,48,49]$.

For the explanation of the effect of nitrogen, it is supposed that nitride ions replace the $\mathrm{O}^{2-}$ in the anatase 


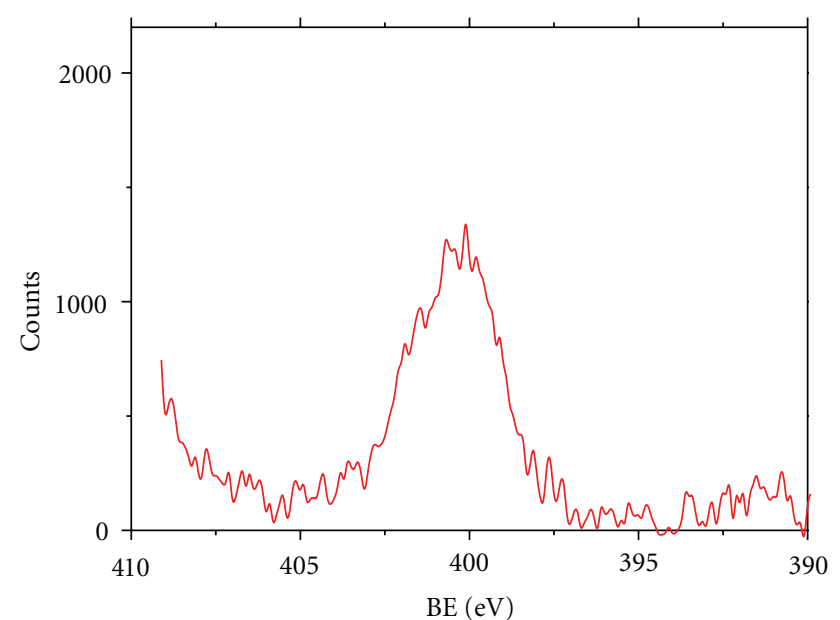

FIgUre 7: XPS peak of $\mathrm{N}_{1 \mathrm{~s}}$ in the sample TIT 144 ground with ammonium carbamate addition.
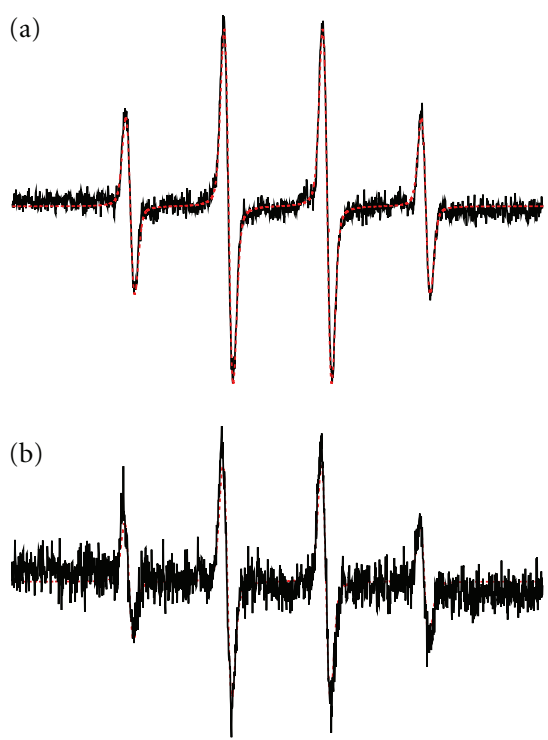

$\begin{array}{cccc}1 & 1 & 1 & 1 \\ 332 & 334 & 336 & 338 \\ & \text { Magnetic field }(\mathrm{mT}) & \end{array}$

FIGURE 8: Experimental (solid line) and simulated (dotted line) EPR spectra of ${ }^{\circ} \mathrm{DMPO}-\mathrm{OH}$ adduct obtained upon irradiation of aqueous TiT 144 ground suspensions in the presence of DMPO $\left(c_{\text {TiT } 144}=0.875 \mathrm{gl}^{-1}, c_{0, \mathrm{DMPO}}=0.025 \mathrm{moll}^{-1}\right)$ : (a) Pyrex $(\lambda>$ $300 \mathrm{~nm}), \cdot$ DMPO-OH concentration of $1.1 \mu \mathrm{mol} 1^{-1}$ was monitored during 660 seconds of irradiation; (b) GG 435 filter $(\lambda>435 \mathrm{~nm})$, -DMPO-OH concentration of $0.3 \mu \mathrm{moll}^{-1}$ was measured during 1350 seconds of irradiation.

structure and create Fermi level in the electronic structure $[12,13]$. To excite the electrons from the valence band into this level requires less energy than the excitation to the conduction band.

Different with the intrinsic excitation of $\mathrm{TiO}_{2}$ under UV irradiation, the excitation behaviour of doped $\mathrm{TiO}_{2}$ under visible irradiation is suggested involving the $\mathrm{Fe}^{3+}$ ion. The

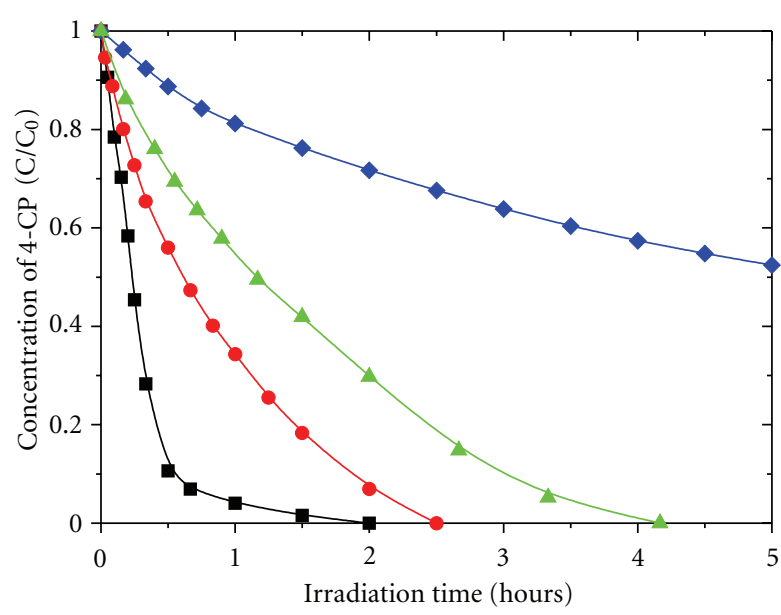

(a)

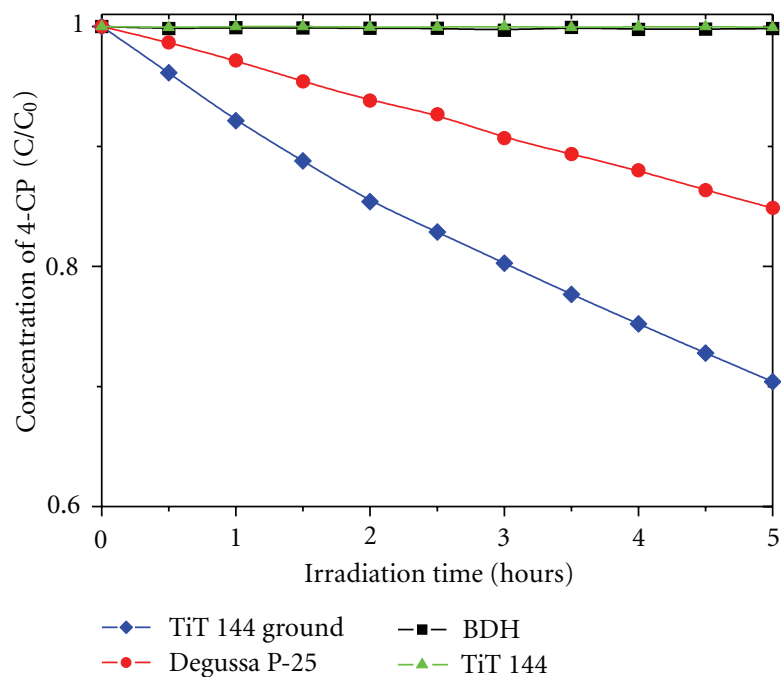

(b)

Figure 9: Photocatalyzed decomposition of 4-CP under UV (a) and vis (b) light.

t2g level of $3 \mathrm{~d}$ orbital of $\mathrm{Fe}^{3+}$ is above the valence band of $\mathrm{TiO}_{2}$, which can absorb a photon with a wavelength around $415 \mathrm{~nm}$ to produce a Fe${ }^{4+}$ ion and a $\mathrm{TiO}_{2}$ conductive band electron (1). Conductive band electrons react with adsorbed $\mathrm{O}^{2}$ to form $\mathrm{O}^{2-}(2)$, while $\mathrm{Fe}^{4+}$ reacts with surface hydroxyl group to produce hydroxyl radical. Therefore, 4chlorophenol can be photodegraded even under the visible light irradiation [49]. Another additional possible reason is the photo-induced electron transfer transition between $\mathrm{Fe}^{3+}$ themselves, which results in a broad absorption around $500 \mathrm{~nm}$ and produces $\mathrm{Fe}^{2+}$ and $\mathrm{Fe}^{4+} . \mathrm{Fe}^{2+}$ and $\mathrm{Fe}^{4+}$ then react with $\mathrm{O}_{2}$ and surface hydroxyl group to produce $\mathrm{O}_{2}{ }^{-}$and hydroxyl radical [49], which degrade 4-chlorophenol,

$$
\begin{gathered}
\mathrm{Fe}^{3+}+h \nu \longrightarrow \mathrm{Fe}^{4+}+\mathrm{ecb}^{-} \\
\mathrm{ecb}^{-}+\mathrm{O}^{2} \longrightarrow \mathrm{O}^{2-} .
\end{gathered}
$$

The observed high photoactivity of the studied sample can be therefore ascribed to synergic effect of small crystal size 
(resulting from effect of ammonium carbamate) and surface doping of $\mathrm{TiO}_{2}$ by $\mathrm{Fe}$ and $\mathrm{N}$ (originating from ammonium carbamate and abrasive wear of the steel from the grinding apparatus).

\section{Conclusions}

Addition of ammonium carbamate to nanocrystalline anatase subjected to high intensity grinding retards growth of anatase crystals and their phase transformation to rutile. This effect can be used for modification of properties of anatase by grinding without undesirable growth of nanocrystals and phase transition to rutile. The grinding product obtained after grinding nanoparticulate anatase TIT 144 for $1.7 \mathrm{hrs}$ as well as the product obtained after annealing to $400^{\circ} \mathrm{C}$ contain $\mathrm{Fe}$ and $\mathrm{N}$ as trace impurities. The annealed sample exhibits remarkable photocatalytic activity under visible light as it was demonstrated by both measurement of kinetics of photocatalytic decomposition of 4-chlorophenol and formation of $\mathrm{OH}^{\bullet}$ radical proved by EPR measurements.

\section{Acknowledgment}

This work was supported by the Ministry of Education of the Czech Republic Project 1M4531477201.

\section{References}

[1] A. Fujishima and K. Honda, "Electrochemical photolysis of water at a semiconductor electrode," Nature, vol. 238, no. 5358, pp. 37-38, 1972.

[2] A. Sobczynski and A. Dobosz, "Water purification by photocatalysis on semiconductors," Polish Journal of Environmental Studies, vol. 10, no. 4, pp. 195-205, 2001.

[3] J. Peral, X. Domenech, and D. F. Ollis, "Heterogeneous photocatalysis for purification, decontamination and deodorization of air," Journal of Chemical Technology and Biotechnology, vol. 70, no. 2, pp. 117-140, 1997.

[4] N. Getoff, "Purification of drinking-water by Irradiationa review," Proceedings of the Indian Academy of SciencesChemical Sciences, vol. 105, pp. 373-391, 1993.

[5] D. F. Ollis, "Integrating photocatalysis and membrane technologies for water treatment," in Advanced Membrane Technology, vol. 984, pp. 65-84, The New York Academy of Sciences, New York, NY, USA, 2003.

[6] L. Petrov, V. Iliev, A. Eliyas, D. Tomova, and G. L. Puma, "Photocatalytic properties of modified $\mathrm{TiO}_{2}$ coatings for purification of waste water and air," Journal of Environmental Protection and Ecology, vol. 8, pp. 881-909, 2007.

[7] S. B. Wang, H. M. Ang, and M. O. Tade, "Volatile organic compounds in indoor environment and photocatalytic oxidation: state of the art," Environment International, vol. 33, no. 5, pp. 694-705, 2007.

[8] J. Zhao and X. D. Yang, "Photocatalytic oxidation for indoor air purification: a literature review," Building and Environment, vol. 38, no. 5, pp. 645-654, 2003.

[9] T. Kudo, Y. Kudo, A. Ruike, A. Hasegawa, M. Kitano, and M. Anpo, "The design of highly active rectangular columnstructured titanium oxide photocatalysts and their application in purification systems," Catalysis Today, vol. 122, no. 1-2, pp. 14-19, 2007.
[10] Y. Cong, L. Xiao, J. L. Zhang, F. Chen, and M. Anpo, "Preparation and characterization of nitrogen-doped $\mathrm{TiO}_{2}$ photocatalyst in different acid environments," Research on Chemical Intermediates, vol. 32, no. 8, pp. 717-724, 2006.

[11] M. Anpo and M. Takeuchi, "The design and development of highly reactive titanium oxide photocatalysts operating under visible light irradiation," Journal of Catalysis, vol. 216, no. 1-2, pp. 505-516, 2003.

[12] R. Asahi, T. Morikawa, T. Ohwaki, K. Aoki, and Y. Taga, "Visible-light photocatalysis in nitrogen-doped titanium oxides," Science, vol. 293, no. 5528, pp. 269-271, 2001.

[13] R. Asahi, T. Morikawa, T. Ohwaki, K. Aoki, and Y. Taga, "Photocatalysts sensitive to visible light," Science, vol. 295, no. 5555, pp. 626-627, 2002.

[14] V. Balek, D. Li, J. Subrt et al., "Characterization of nitrogen and fluorine co-doped titania photocatalyst: effect of temperature on microstructure and surface activity properties," Journal of Physics and Chemistry of Solids, vol. 68, no. 5-6, pp. 770-774, 2007.

[15] V. Balek, J. Subrt, I. M. Bountseva, H. Irie, and K. Hashimoto, "Emanation thermal analysis study of $\mathrm{N}$-doped titania photoactive powders," Journal of Thermal Analysis and Calorimetry, vol. 92, no. 1, pp. 161-167, 2008.

[16] V. Balek, J. Subrt, H. Irie, and K. Hashimoto, "Thermal behavior of $\mathrm{TiO}_{2}-\mathrm{xNx}$ nanostructured powder," International Journal of Photoenergy, vol. 2008, Article ID 267345, 7 pages, 2008.

[17] M. Mrowetz, W. Balcerski, A. J. Colussi, and M. R. Hoffmann, "Oxidative power of nitrogen-doped $\mathrm{TiO}_{2}$ photocatalysts under visible illumination," Journal of Physical Chemistry B, vol. 108, no. 45, pp. 17269-17273, 2004.

[18] T. Ohno, M. Akiyoshi, T. Umebayashi, K. Asai, T. Mitsui, and M. Matsumura, "Preparation of S-doped $\mathrm{TiO}_{2}$ photocatalysts and their photocatalytic activities under visible light," Applied Catalysis A, vol. 265, no. 1, pp. 115-121, 2004.

[19] T. Ohno, T. Mitsui, and M. Matsumura, "Photocatalytic activity of S-doped $\mathrm{TiO}_{2}$ photocatalyst under visible light," Chemistry Letters, vol. 32, no. 4, pp. 364-365, 2003.

[20] S. Sakthivel and H. Kisch, "Daylight photocatalysis by carbonmodified titanium dioxide," Angewandte Chemie International Edition, vol. 42, no. 40, pp. 4908-4911, 2003.

[21] T. Umebayashi, T. Yamaki, H. Itoh, and K. Asai, "Band gap narrowing of titanium dioxide by sulfur doping," Applied Physics Letters, vol. 81, no. 3, pp. 454-456, 2002.

[22] T. Umebayashi, T. Yamaki, S. Tanaka, and K. Asai, "Visible light-induced degradation of methylene blue on S-doped $\mathrm{TiO}_{2}$," Chemistry Letters, vol. 32, no. 4, pp. 330-331, 2003.

[23] R. Asahi and T. Morikawa, "Nitrogen complex species and its chemical nature in $\mathrm{TiO}_{2}$ for visible-light sensitized photocatalysis," Chemical Physics, vol. 339, no. 1-3, pp. 57-63, 2007.

[24] Y. Nakano, T. Morikawa, T. Ohwaki, and Y. Taga, "Origin of visible-light sensitivity in $\mathrm{N}$-doped $\mathrm{TiO}_{2}$ films," Chemical Physics, vol. 339, no. 1-3, pp. 20-26, 2007.

[25] C. Di Valentin, E. Finazzi, G. Pacchioni et al., "N-doped $\mathrm{TiO}_{2}$ : theory and experiment," Chemical Physics, vol. 339, no. 1-3, pp. 44-56, 2007.

[26] X. F. Qiu and C. Burda, "Chemically synthesized nitrogendoped metal oxide nanoparticles," Chemical Physics, vol. 339, no. 1-3, pp. 1-10, 2007.

[27] Y. Cui, H. Du, and L. S. Wen, "Doped- $\mathrm{TiO}_{2}$ photocatalysts and synthesis methods to prepare $\mathrm{TiO}_{2}$ films," Journal of Materials Science and Technology, vol. 24, no. 5, pp. 675-689, 2008. 
[28] B. Ohtani, "Preparing articles on photocatalysis - beyond the illusions, misconceptions, and speculation," Chemistry Letters, vol. 37, no. 3, pp. 217-229, 2008.

[29] X. L. Yan, T. Ohno, K. Nishijima, R. Abe, and B. Ohtani, "Is methylene blue an appropriate substrate for a photocatalytic activity test? A study with visible-light responsive titania," Chemical Physics Letters, vol. 429, no. 4-6, pp. 606-610, 2006.

[30] P. G. McCormick and F. H. Froes, "The fundamentals of mechanochemical processing," Journal of the Minerals, Metals and Materials, vol. 50, no. 11, pp. 61-65, 1998.

[31] S. Begincolin, G. Lecaer, A. Mocellin, and M. Zandona, "Polymorphic transformations of titania induced by ballmilling," Philosophical Magazine Letters, vol. 69, no. 1, pp. 1-7, 1994.

[32] T. Girot, X. Devaux, S. Begin-Colin, G. Le Caer, and A. Mocellin, "Initial stages of the transformation of singlecrystal anatase particles during high-energy ball milling," Philosophical Magazine A, vol. 81, no. 2, pp. 489-499, 2001.

[33] C. Real, J. M. Criado, and V. Balek, "Use of emanation thermal analysis in characterization of the influence of grinding on textural and structural properties of nanosized titania powders," Journal of Materials Science, vol. 33, no. 21, pp. 5247-5254, 1998.

[34] C. Real, L. Garcia, M. D. Alcala, and J. M. Criado, "Influence of grinding on the sintering properties of rutile," Solid State Ionics, vol. 141-142, pp. 671-675, 2001.

[35] M. Uzunova-Bujnova, D. Dimitrov, D. Radev, A. Bojinova, and D. Todorovsky, "Effect of the mechanoactivation on the structure, sorption and photocatalytic properties of titanium dioxide," Materials Chemistry and Physics, vol. 110, no. 2-3, pp. 291-298, 2008.

[36] P. Billik, G. Plesch, V. Brezova, L. Kuchta, M. Valko, and M. Mazur, "Anatase $\mathrm{TiO}_{2}$ nanocrystals prepared by mechanochemical synthesis and their photochemical activity studied by EPR spectroscopy," Journal of Physics and Chemistry of Solids, vol. 68, no. 5-6, pp. 1112-1116, 2007.

[37] M. J. Diánez, J. M. Criado, L. A. Pérez-Maqueda, J. Subrt, and E. Donoso, "Estudio de las transiciones de fase del $\mathrm{TiO}_{2}$ por aportación de energía mecánica," in Proceedings of the 8th Congreso Iberoamericano de Energía Mecánica, pp. 1683-1689, Cuzco, Peru, October, 2007.

[38] S. Bakardjieva, J. Subrt, V. Stengl, M. J. Dianez, and M. J. Sayagues, "Photoactivity of anatase-rutile $\mathrm{TiO}_{2}$ nanocrystalline mixtures obtained by heat treatment of homogeneously precipitated anatase," Applied Catalysis B, vol. 58, no. 3-4, pp. 193-202, 2005.

[39] J. Šubrt, J. Boháček, V. Štengl, T. Grygar, and P. Bezdička, "Uniform particles with a large surface area formed by hydrolysis of $\mathrm{Fe}_{2}\left(\mathrm{SO}_{4}\right)_{3}$ with urea," Materials Research Bulletin, vol. 34, no. 6, pp. 905-914, 1999.

[40] J. Subrt, V. Stengl, S. Bakardjieva, and L. Szatmary, "Synthesis of spherical metal oxide particles using homogeneous precipitation of aqueous solutions of metal sulfates with urea," Powder Technology, vol. 169, no. 1, pp. 33-40, 2006.

[41] H. Bastlova, "Determination of specific surface area of anatase by physical adsorption of noble-gases," Collection of Czechoslovak Chemical Communications, vol. 40, pp. 3100-3107, 1975.

[42] B. D. Cullity and S. R. Stock, Elements of X-Ray Diffraction, Prentice Hall, New York, NY, USA, 3rd edition, 2001.

[43] S. Begin-Colin, T. Girot, A. Mocellin, and G. Le Caer, "Kinetics of formation of nanocrystalline $\mathrm{TiO}_{2}$ II by high energy ballmilling of anatase $\mathrm{TiO}_{2}$," Nanostructured Materials, vol. 12, no. 1, pp. 195-198, 1999.
[44] X. Y. Pan, Y. Chen, X. M. Ma, and L. H. Zhu, "Phase transformation of nanocrystalline anatase powders induced by mechanical activation," Journal of the American Ceramic Society, vol. 87, no. 6, pp. 1164-1166, 2004.

[45] Y. Cong, J. L. Zhang, F. Chen, M. Anpo, and D. N. He, "Preparation, photocatalytic activity, and mechanism of nano$\mathrm{TiO}_{2}$ co-doped with nitrogen and iron (III)," Journal of Physical Chemistry C, vol. 111, no. 28, pp. 10618-10623, 2007.

[46] A. S. W. Li, K. B. Cummings, H. P. Roethling, G. R. Buettner, and C. F. Chignell, "A spin-trapping database implemented on the IBM PC/AT," Journal of Magnetic Resonance, vol. 79, no. 1, pp. 140-142, 1988.

[47] V. Brezova, D. Dvoranova, and A. Stasko, "Characterization of titanium dioxide photoactivity following the formation of radicals by EPR spectroscopy," Research on Chemical Intermediates, vol. 33, no. 3-5, pp. 251-268, 2007.

[48] D. H. Kim, H. S. Hong, S. J. Kim, J. S. Song, and K. S. Lee, "Photocatalytic behaviors and structural characterization of nanocrystalline Fe-doped $\mathrm{TiO}_{2}$ synthesized by mechanical alloying," Journal of Alloys and Compounds, vol. 375, no. 1-2, pp. 259-264, 2004.

[49] J. F. Zhu, F. Chen, J. L. Zhang, H. J. Chen, and M. Anpo, " $\mathrm{Fe}^{3+}-$ $\mathrm{TiO}_{2}$ photocatalysts prepared by combining sol-gel method with hydrothermal treatment and their characterization," Journal of Photochemistry and Photobiology A, vol. 180, no. 1-2, pp. 196-204, 2006. 


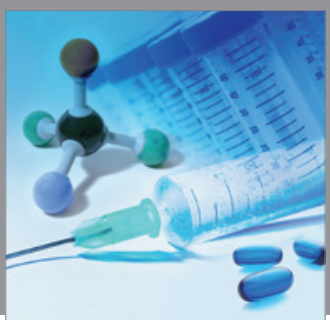

International Journal of

Medicinal Chemistry

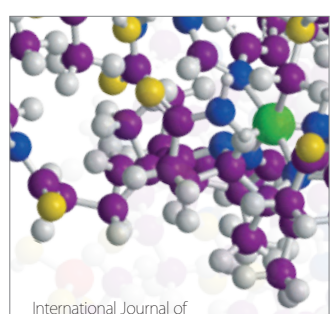

Carbohydrate Chemistry

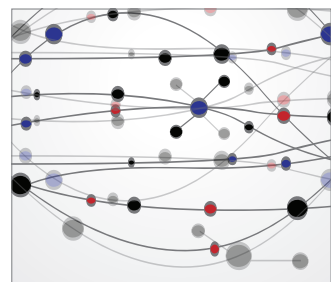

The Scientific World Journal
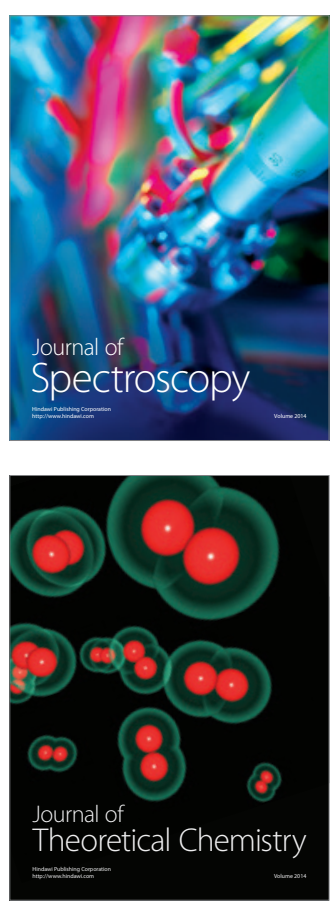
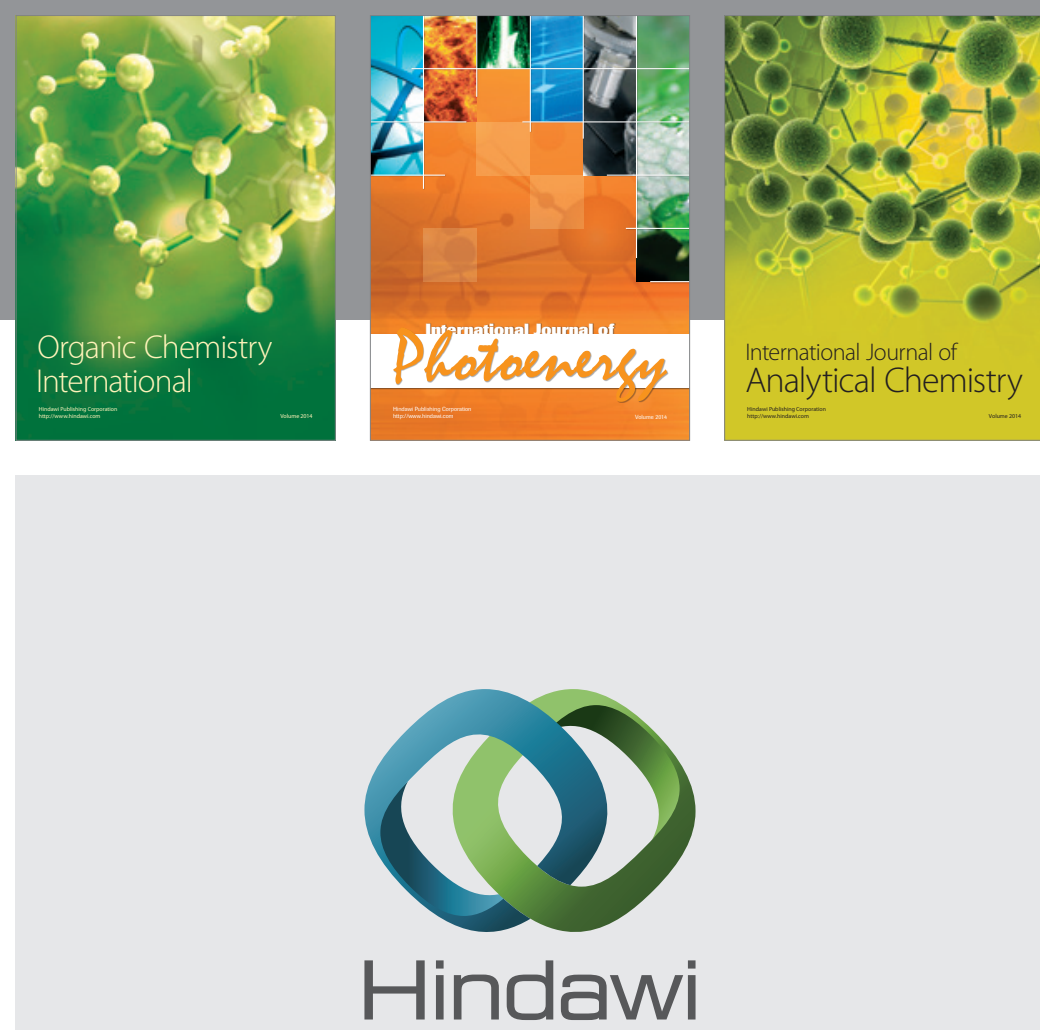

Submit your manuscripts at

http://www.hindawi.com
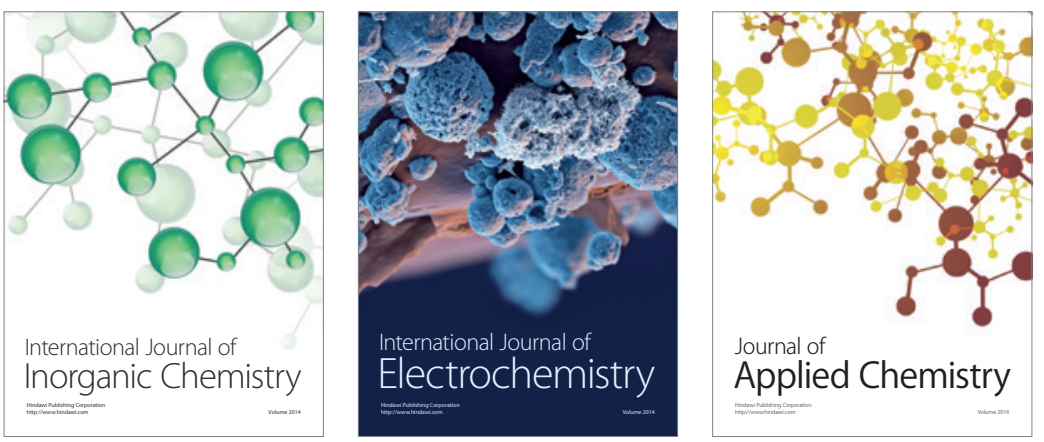

Journal of

Applied Chemistry
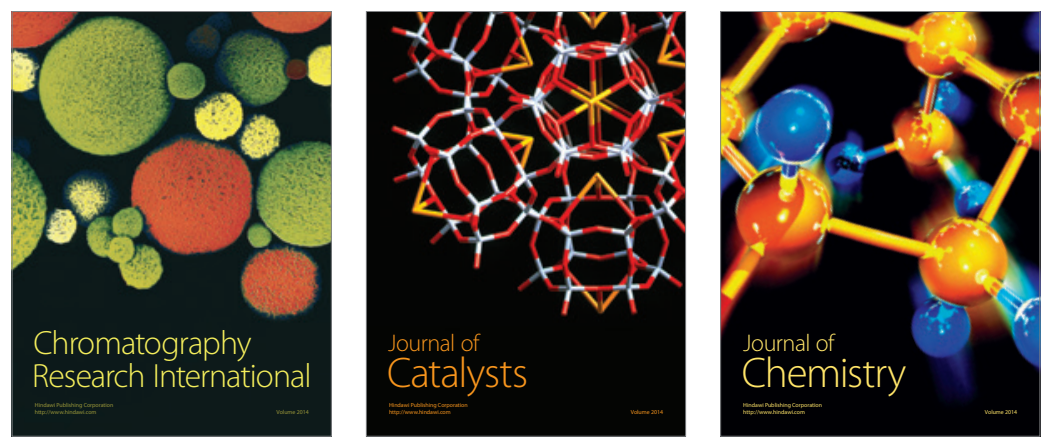
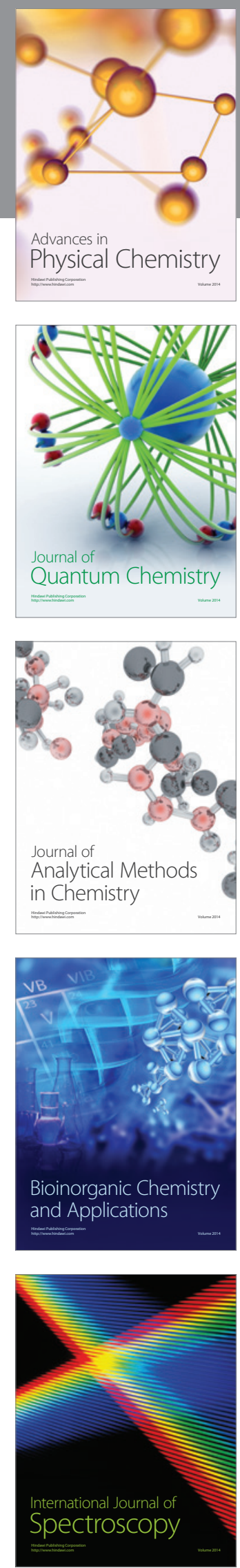